\title{
Socio-Legal Aspects of Mental Illness
}

\author{
Prabhakararao Samapthirao ${ }^{1 *}$
}

\section{ABSTRACT}

Mental health is not an exception to the social constructs that surrounds it. Although, some progress has been achieved in understanding the dimensions of stigma against mental illness, and the processes by which public stereotypes are translated into discriminatory behavior, much more needs to be researched upon. Myths and misconceptions about mental diseases are continually reinforced by stereotypical and often destructive media images. Mentally ill have fundamental / human right to receive mental health care and to humane living conditions in their families, communities and mental hospitals. Societal support to the vulnerable groups like mentally ill is picking up more momentum in the recent years. Prevention is often overlooked, under-funded and neglected components of mental health.

\section{Keywords: Socio-Legal Aspects, Mental Illness}

Mental health refers to inner harmony of an individual personal pre-disposition whereas the social health connotes external harmony of an individual adjustment to social and environmental factors around him. The mental health looks at how one solves his/her own internal conflicts, the level of self-esteem, needs, problems, goals and ability to strike a balance between rationality and emotionality. If we examine the history of mental health and illnesses in India, mental health from its very beginning viewed as incurable as it is disease inherited idiosyncrasy or family 'curse', or a lifelong affliction with near supernatural origins. As a result, treatment falls beyond the reach of science and rationality. This is one of the major factors in influencing our attitude, perception and understanding of mental health and illnesses. Even today, we are unable to challenge these stereotyped beliefs, myths and this is one of our greatest drawbacks in the achievement of our goals about mental health(1).

A few centuries ago mental patients were locked up in 'madhouses' and thereafter they were given shelter in mental asylums away from the harassment of the society that neither understand nor tolerate their behavior. After some decades, mental hospitals appeared on the scene to treat

\footnotetext{
${ }^{1}$ Health Education Officer, Central Health Education Bureau (Cheb) Central Health Education Bureau Kotla Road, New Delhi, India

*Responding Author

(C) 2016 I P Samapthirao; licensee IJIP. This is an Open Access Research distributed under the terms of the Creative Commons Attribution License (http://creativecommons.org/licenses/by/2.0), which permits unrestricted use, distribution, and reproduction in any Medium, provided the original work is properly cited.
} 


\section{Socio-Legal Aspects of Mental Illness}

mentally ill patients. Today we have 'mental health institutes' which provide a variety of services like care, treatment and rehabilitation of mentally ill and also programmes for prevention and promotion of mental health. Erwadi Tragedy in 2001which took away the lives of 28 inmates of a faith-based mental asylum by the fire when were bound by chains at Moideen Badusha Mental Home in Erwadi Village in Tamil Nadu. The incident revealed bleak state of affairs of mental health care in the country about supernatural beliefs, its incurability, lack of services and lack of recognition for human rights. In the same years Supreme Court directed the central government to take the responsibility of mental health care and to expand community mental health services to the whole country with more emphasis on human rights.

\section{Stigma \& Stereotypes}

People with serious mental illness not only struggle with the symptoms and disabilities that are associated with the disease but are also robbed of their legitimate life opportunities due to stereotypes and prejudices that surrounded with the misconceptions about the disease. The impact of stigma against mental illnesses are twofold, public stigma which is the reaction of general public towards the people with mental illness and self-stigma is the prejudice which people with mental illness turn against themselves. Both public and self-stigma have three common components viz. Stereotypes, prejudice, and discrimination. Several themes describe misconceptions about mental illness and corresponding stigmatizing attitudes. Media analyses of film and print have identified that the people with mental illness are homicidal maniacs and should be feared at once. Stereotypes are "social" because they represent collectively agreed upon notions of groups and they are "efficient" because people can quickly create impressions and expectations of other group of individuals who are themselves stereotyped.

The media are essential players in any movement for change, as they have an important role in determining public attitudes to mental illness. The sad reality is that, for most people with schizophrenia, living in the community does not mean being part of the community. There is need to ensure that the treatment package includes not only access to good clinical care, but a range of other factors such as community accommodation and rehabilitation programs, family education and support, respectful and welcoming attitude of health professionals and community members.

Change strategies for public stigma have been grouped into three approaches i.e., protest, education, and contact. Groups protest false and hostile images of mental illness as a way to challenge the stigmas they represent. These efforts send two messages to the media and the public, first media to stop reporting such inaccurate images of mental illness and to the public to stop believing such negative views about mental illness. In recent years, citizens are encountering far fewer sanctioned examples of stigma and stereotypes because of such protest efforts. Circumstantial evidence suggests that protest campaigns have been effective in getting stigmatizing images of mental illness withdrawn. (2). 


\section{Socio-Legal Aspects of Mental Illness}

\section{International scenario:}

By the year 1978, Italy came out with a revolutionary mental health law in tune with the historical context with a focus on human rights, deinstitutionalization of services, care in the community, partnership with patients, families etc. In the year 2001 WHO in its World Health Report made several recommendations for incorporate provisions for treatment of mentally ill in the community i.e., within the primary health care setup involving communities, families and patients. Accessibility and availability of all psychotropic medicines and education to the patients also emphasized.

In 1991, minimum human rights standards of practice in the mental health field were established. International oversight and enforcement bodies have used the MI Principles as an authoritative interpretation of the requirements of international conventions such as the ICESCR(11). As a policy guidance instrument, the Standard Rules for equalization opportunities for persons with disabilities reiterate the goals of prevention, rehabilitation and equalization of opportunities established by the World Programme of Action (12).

The Caracas declaration which has major implications for the structure of mental health services, states that exclusive reliance on inpatient treatment in a psychiatric hospital isolates patients from their natural environment, thereby generating greater disability. The Declaration establishes a critical link between mental health services and human rights by concluding that outmoded mental health services put patients' human rights at risk. The Declaration also advocated to promote community-based and integrated mental health services by suggesting a restructuring of existing psychiatric care. It states that resources, care and treatment for persons with mental disorders must safeguard their dignity and human rights, provide rational and appropriate treatment, and strive to maintain persons with mental disorders in their communities. It further states that mental health legislation must safeguard the human rights of persons with mental disorders, and services should be organized so as to provide for enforcement of those rights(13).

International associations of mental health professionals have also declared to protect the human Rights of persons with mental disorders by issuing their own sets of guidelines (Madrid Declaration) for standards of professional behaviour and practices, the declaration insists on treatment based on partnership with persons with mental disorders, and on enforcing involuntary treatment only under exceptional circumstances (14). In 1996, WHO developed the Mental Health Care Law: Ten Basic Principles as a further interpretation of the MI Principles and as a guide to assist countries in developing mental health laws. In 1996, WHO also developed Guidelines for the Promotion of Human Rights of Persons with Mental Disorders, which is a tool to help understand and interpret the MI Principles and evaluate human rights conditions in institutions (15). In 1994, the World Conference on Special Needs Education adopted which affirmed the right to integrated education for children with mental disabilities. This is of 


\section{Socio-Legal Aspects of Mental Illness}

particular importance in implementing the World Declaration on Education for All(WDEA) and enforcing the right to education established under the ICESCR (16)

\section{Legal aspects:}

Another very important issue related to the mental health is its legal aspects. The important legal milestones in India include passing of Narcotic and psychotropic Substance Act 1985, Mental Health Act 1987 and persons with Disability Act 1995. Mental Health Act 1987 was promulgated with new provisions like demystification of mental illness, simplification of admission/discharge procedures and putting more emphasis on protection of the interest of the mentally ill and their well-being. It has introduced more humanitarian considerations to prevent any indignity or cruelty to the mentally ill. But the act was never implemented in its true spirit. Many provisions of the outdated Indian Lunacy Act 1912 like custodial care and segregation of mental patients from the mainstream community are still in vogue. In the medieval ages, it was believed that people going to prison, sanatoria and mental asylums go only to die and never comeback. Persons with mental disorders, however, may require special and additional Protection in view of a history of human rights abuses, stigma and discrimination and, at times, due to the peculiarities of mental disorders. People with mental disorders are sometimes treated as "nonpersons", akin to the way children or worse, animals are treated. They are often considered to lack adult decision making capacity, which results in a total disregard for their feelings and human dignity.

\section{Major human rights standards applicable to mental health:}

The serious mentally ill persons are a special group with disabilities and they are entitled to all human and fundamental rights which are guaranteed to disabled by the constitution of India, The fundamental right to life and liberty as interpreted by the Supreme Court of India in number of landmark cases includes the right to live with human dignity in accordance with the article 21 of the constitution of India. Rights of the patients with mental illness include right to get treatment with his/her own consent. These rights also dealt treatment under special circumstances, where the patient does not have judgement into his condition then treatment to be administered in his best interest. As soon as the conditions for compulsory treatment are no longer applicable, psychiatrist should obtain voluntary consent and treat the patient (3). These rights inter alia involve

Confidentiality: Persons with mental disorders have the right of confidentiality of information about themselves and their illness and treatment; such information should not be revealed to third parties without their consent. All professionals involved in the care of persons with mental disorders should be aware of such rules and are duty bound by professional codes of conduct that generally include rules against breach of any confidentiality. Authorities in charge of mental health facilities should also ensure that adequate processes with effective systems are in place to safeguard the confidentiality of persons with mental disorders, so that only authorized 


\section{Socio-Legal Aspects of Mental IIIness}

individuals have access information about them. There are also other issues in the confidentiality that the need of mental health professionals to share certain information about the patients with their primary caregivers and the rights of patients and their personal representatives to access information like clinical health records maintained by the mental health facilities for the purpose of initiating judicial review, or appeal against the decision that was already taken (4).

Mentally affected persons staying in mental health facilities are often subject to poor living conditions, such as lack of or inadequate clothing, poor sanitation and hygiene, insufficient and poor quality food, lack of privacy, being forced to work, or being subject to physical, mental and sexual abuse(5). Patients admitted to mental health facilities have the right to be protected from cruel, inhuman and degrading treatment (6).The provision of a safe and hygienic environment is a health concern, and critical to a person's overall well-being and it should be close to normal life which includes facilities for leisure, education, religious practice and vocational rehabilitation. No individual should be subject to unsafe or unsanitary conditions when receiving mental health treatment.

Privacy is a limitation upon the society members to intrude into the personal life of others. It is quite common in the mental health facilitates to violate privacy concerns like forcing patients to live for years in dormitory-like wards or "human warehouses "that provide little private space. However, in certain circumstances such as that of a suicidal patient who cannot be searched or continually kept under observation for his or her own protection. This limitation should be carefully considered against the internationally accepted right of Privacy. Patients admitted involuntarily (forcefully or against their willingness) often restricted to communicate even with their most intimate relatives and friends, but, they have the right to communicate with the outside world barring exceptions on confidentiality and access to information.

There is also an urgent need to prevent forced labour in mental health facilities in menial jobs by mentally ill persons due to shortage of staff etc., however, there should clarity between forcedlabour, occupational therapy and occupational rehabilitation. Mentally ill persons and their relatives may not know about the rights that are available to them and suffer silently against their abuse. It is, therefore, essential to educate patients and their relatives about their rights when interacting with mental health services. Family members often bear the brunt of the person's behavior when he or she is ill or relapses and they too become targets of stigma and discrimination. In some countries, families and caregivers also carry the legal responsibility for third-party liability arising from actions of persons with mental disorders. Therefore, Family members and caregivers need complete information about the illness and treatment plans to enable to look after their ill relatives and should not be arbitrarily refused information simply on grounds of confidentiality. 


\section{Socio-Legal Aspects of Mental IIIness}

\section{Informed consent voluntarily admitted patients:}

Free and informed consent should form the basis of the treatment and rehabilitation of most people with mental disorders. Where the patient has the capacity to give informed consent, such consent is a prerequisite for treatment. "No treatment shall be given to a patient without his or her informed consent, except as provided as provide otherwise [MI principles: informed consent]. In persons with severe mental disorders where the person lost the ability to make informed choices and decisions affecting their lives, it is important to appoint another person who is able to act on their behalf and in the best interest of the person. The right to consent to treatment also implies the right to refuse treatment. Voluntary admission brings with it the right to voluntary discharge from mental health care facilities, lack of protest should not be construed as consent, since consent must be voluntary and informed.

People unable to give informed consent are the persons who are not a safety risk to themselves or to others. It is crucial that the rights of non-protesting patients, users who are incapable, due to their mental health status, to give consent to treatment and/or admission, but who do not refuse mental health interventions. Their admission and treatment rights are protected in a similar manner to those of involuntary users.

Informed consent from non-protesting patients should, like involuntary users, qualify for mandatory automatic review procedure and have the right to appeal their position along with other existing rights such as right to notification of their rights, to confidentiality, to adequate standards of care and other rights. The fundamental principles of "least restrictive environment" and "in the best interest of the patient" must similarly be applied to non-protesting patients. If users object to their admission or treatment, they must immediately stop being regarded as "nonprotesting" and the full criteria for determining involuntary admission and treatment must be applied. Similarly, if, following their admission/treatment, they regain the capacity to make informed decisions; they must be removed from this status.

\section{Involuntary admission and treatment:}

Involuntary or compulsory admission is generally permitted only if all the following criteria are met and the patient is refusing voluntary admission viz. that there is evidence of a mental disorder of specified severity, and there is a serious likelihood of immediate or imminent harm to self or others, and/or a deterioration in the patient's condition if treatment is not given admission includes a therapeutic purpose, and this treatment can only be given by an admission to a mental health facility. Involuntary admission impinges on personal liberty and the right to choose, and they carry the risk of abuse for political, social and other reasons. On the other hand, involuntary admission and treatment can prevent harm to self and others, and useful to people in attaining their right to health, which, due to their mental disorder, they are unable to manage voluntarily otherwise. 


\section{Socio-Legal Aspects of Mental IIIness}

In an emergency, involuntary admission and treatment should be permitted on the assessment and advice of a qualified medical or other appropriate practitioner. Emergency treatment must be time-limited (usually no longer than 72 hours), and substantive procedures for involuntary admission and treatment, if necessary, must be initiated as soon as possible and completed within this period. Emergency treatment should not include depot narcoleptics, major medical and surgical procedures, ECT, sterilization, psychosurgery and other irreversible treatment.

Physical restraint or involuntary seclusion of a patient shall not be resorted to, except in accordance with the officially approved procedures of the mental health facility and only and when it is the last of all means available to prevent immediate or imminent harm to the patient or others. It should not be prolonged beyond the period for which is strictly necessary for this purpose. In all cases of physical restraint or involuntary seclusion, the reasons for them and their nature and extent shall be recorded in the patient's medical record. A patient who is restrained or secluded shall be kept under humane conditions and be under the care and close and regular supervision of qualified members of the staff. A personal representative, if any and if relevant, shall be given prompt notice of any physical restraint or involuntary seclusion of the patient $(5,6,7,8)$

However, it is important to stress that involuntary admission and treatment required only for a minority of patients who are suffering from mental disorders; in many instances where patients are admitted and treated involuntarily, if humane treatment and a proper opportunity for voluntary care were provided, involuntary admission and treatment could be reduced further. It is acknowledged that some user and advocacy groups, vehemently opposed to the idea of involuntary treatment, including the involuntary administration of psychotropic medicines, under any circumstances (9)

\section{Clinical and Experimental Research:}

Informed consent for participation in clinical or experimental research must be obtained from all patients who have the capacity to consent. This is applicable to both voluntary and involuntary patients. .No one shall be subject to torture or to cruel, inhuman or degrading treatment or punishment. In particular, no one shall be subject without his free consent to medical or scientific experimentation. (6). "clinical trials and experimental research shall never be carried out on any patient without informed consent, except that a patient who is unable to give informed consent may be admitted to a clinical trial or given experimental treatment, but only with the approval of a competent, independent review body specifically constituted for this purpose". As per the International Ethical Guidelines for Biomedical Research Involving Human Subjects (10) consent may be allowed in biomedical research with proxy consent, or consent from a properly authorized representative, involving individuals who are incapable of giving informed consent. Where informed consent cannot be obtained, should be carefully followed (MI Principle 11). 


\section{Socio-Legal Aspects of Mental IIIness}

\section{Social Support for person with mental disabilities}

In view of the linkages between social and psychological problems and mental health social support in the existing of social structure is very essential to the mentally afflicted persons. The social workers for the first time allied with the mental health establishment and worked in hospitals. A social worker is a person who connects patients with mental disorders, hospital family and wider community. He tries to build a rapport with the patient to win his support cooperation and trust with staff the involved in the process of treatment. He helps the patient in using the family and community resources for his protection and restoration of his health to normal. He helps to sustain hope and interest in family employment and community while he is undergoing treatment and rehabilitation. The role of psychiatric social workers at micro level in community mental health services include brief psycho social assessment, brief therapy and placement services. At macro level include group psychotherapy, group psycho education, group work with children and family psycho education, family counselling and family therapy. NGOs like AMEND, Bengaluru, Asha Chennai, Rashmi Delhi are partnering with families and communities for community mental work.

Reliable statistics regarding incidence of mental morbidity in India are not available. It is estimated that prevalence of mental patients is 2/1000, accordingly 8,00, 000 beds would be required in the hospitals to accommodate mental patients as against existing provision of a little over 10,000 beds for the country as a whole (Bhore committee). The patients' attitude towards the family which was most averse and a major cause of relapse in 1970s gradually changed into that of carer and partner in 1990s. Mental health care was integrated with primary health care in 1975. National mental health programme was launched in 1982 with main components of availability and accessibility of mental health services, application of knowledge to general healthcare (diffusion of mental health skills) and community participation. During 1990s District Mental Health programme, a 100\% centrally sponsored scheme was covered in 25 district over 25 states to make mental health are as part of primary health care in India.

The mental health network includes both prevention and treatment facilities. Mental hospitals are an important part of the mental health service network and generally fall into three categories, State and county hospitals, Veterans Administration Hospitals. Aftercare services help patients in their re-socialization and one such specialized aftercare facility is the 'halfway house 'that provide living arrangements and opportunities for re-establishing work, family, and social relationships on a gradual basis under sheltered conditions. 'Therapeutic clubs' are one of the newer developments in aiding those who have been mentally ill. 'Fountain House' is the first such facility to believe people with emotional disabilities have productive potential, work is important for everyone, everyone needs social relationships and people need adequate housing.

Outpatient psychiatric clinics are widely used for the care of emotionally disturbed children; diagnosis is made through interviews and testing. Treatment is planned to alleviate the problems 


\section{Socio-Legal Aspects of Mental IIIness}

by modifying the child's unacceptable behavior. Difficulty in disciplining, temper tantrums, poor relationships with peers and siblings, and poor adaptation to school are the more frequently encountered problems. Most jails and prisons have inadequate mental health services especially those who suffer from alcohol and drug dependence.

\section{Special Problems and Issues in Mental Health}

The major challenges faced by the mental health field are meager and unevenly distributed human resources for mental health care, substandard training in psychiatry, lack of welfare programmes to cured mental patients, public apathy and ignorance, growth of private sector without proper regulation. Another very serious and important consideration is the expansion of mental health services in to the rural areas where most of the people believe that the mental illnesses are caused by wrath of spirits, demons and ghosts and hence only religious, magical and traditional methods by god men/god women and traditional healers can only alleviate the symptoms.

The number of homeless mentally ill frequently mentioned in the media is about some millions. An increasing number of these are children and women which shows a critical shortage of any kind of housing and employment opportunities. In countries like America "Greyhound therapy" is utilized by giving these people, one-way tickets to other parts of the country. Unless a person has demonstrated that they are a threat to themselves or others, no one can take away the right to freedom. Because of the nature of their illness many are unable to make rational decisions about their care is not considered by the courts.

The number of chronically Mentally Ill estimated by the National Institute of Mental Health and Neurosciences (NIMHANS) is2/1000 population and are almost destitute or NIMBY (not in my backyard), communities refusing to accept this population. In the recent fast an alarming number of farmers' suicides indicate a grave situation. India has one of the world's highest rates of suicides among people aged between 15 years and 29 years accounting 40/1,00,000 population and a third of all suicides in the country. Correlated with sociological, psychological and economic forces suicides high among those who experience repeated school failures and longstanding behavioral problems. Not having family support correlates with high numbers of suicides/attempt rates. The Message of increasing youth suicide indicates employment opportunities for youth are imperative. Success experiences will almost certainly reduce the risk of suicides. All teaching-learning encounters need to emphasize the importance of good coping skills for youth. Learning to deal with stress situations needs to be a high priority educational objective for all youth. As a nation we need to reaffirm the value and worth of good family support systems and the use of the nation's resources to strengthen the family.

Two potentially fertile fields for prevention in mental illness are the public schools and the workplace. There is much unused knowledge of human behavior that could be used to help 
youngsters before the drop out of school, take their own lives, abuse drugs, or turn to premature sex to relieve boredom. Continuing research is needed in the areas like Mysteries of the human mind abound. The mental health need of the elderly have been sorely neglected. By the year 2010, approximately 20 percent of the American population will be 65 years or older. Our nation needs a plan to address the growing mental health needs of our aging population.

\section{OPPORTUNITIES}

The opportunities for mental health work that are available in the country include forging new partnerships with wide variety of community resources, community tolerance, family commitment, limited barriers for professional work, and integration of mental health services with general health services e.g, primary health center based rural mental health programme, general practitioner based urban mental health programme, school mental health programme (early detection and treatment, training of teachers, imparting life skills to students to improve psychosocial competence etc., home based follow-ups of psychiatric patients and community based rehabilitation of minor mentally ill patients.

\section{CONCLUSION}

But everything is not okay with the state of affairs in the field of mental health as the transition from aversion to inclusion was never completed as there was a strong lobby of medical professionals and vested interests that mental illness requires a technical judgment by medically qualified persons only. This politicization of medical profession has mystified the field of health care and promotion and there is strong need to question it as health neither a technical domain of a few experts nor few policy makers. A wider vista of individuals, groups and institutions need to contribute towards the well-being of individuals, families and communities.

\section{REFERENCES}

1. Mental health in India issues and concerns -a commentary- AnanthKumar JNU, New Delhi, India.

2. Understanding the impact of stigma on people with mental illness, patrickwcorrigan and amy c watson)

3. Declaration Of Hawaii 1992 by General Assembly of World Psychiatric association.

4. Human rights and privileges of mentally ill persons ShivGautam, Sanjay Jain, LalitBatra , Rajesh Sharma ,DeeptiMunshi.

5. MI Principles: Rights and conditions in mental health facilities.

6. International Convention on Civil and Political Rights (ICCPR)

7. Protection of Human Rights and Fundamental Freedoms (1950)

8. The Declaration of Hawaii (1983),

9. Mind Freedom Support International Coalition.

10. Human rights watch 


\section{Socio-Legal Aspects of Mental IIIness}

11. The UN Principles for the Protection of Persons with Mental Illness and the Improvement of Mental Health Care (MI Principles))

12. Standard Rules on the Equalization of Opportunities for Persons with Disabilities (Standard Rules, 1993

13. The Declaration of Caracas(1990)

14. Declaration of Madrid (1996

15. WHO Technical Standards.

16. The Salamanca Statement and Framework for Action on Special Needs Education (1994)

How to cite this article: P Samapthirao (2016), Socio-Legal Aspects of Mental Illness, International Journal of Indian Psychology, Volume 3, Issue 3, No. 10, DIP: 18.01.187/20160303, ISBN: 978-1-365-19879-3 